\title{
Investigations into the ex situ methanol, ethanol and ethylene glycol permeabilities of alkaline polymer electrolyte membranes
}

John R. Varcoe, ${ }^{*}$ Robert C. T. Slade, Eric Lam How Yee, Simon D. Poynton, Daniel J. Driscoll

Department of Chemistry, University of Surrey, Guildford GU2 7XH, United Kingdom.

* Corresponding Author: Tel: +44 (0)1483 682616; Fax: +44 (0)1483 686851; E-mail: j.varcoe@surrey.ac.uk

Alkaline anion-exchange membranes (AAEMs) are being developed for metal-cationfree solid alkaline fuel cells. Reduced solvent uptakes were observed after immersion in methanol, ethanol and ethylene glycol relative to a Nafion ${ }^{\circledR}-115$ proton-exchange membrane (PEM); this translated directly into lower alcohol permeabilities. Alkaline polymer electrolytes showed lowered degrees of swelling (membrane thickness), when immersed in methanol and ethanol, relative to Nafion-115. The open circuit voltages, $V_{O C V}$, of the corresponding direct alcohol fuel cells were superior to acid equivalents with membranes of identical fully hydrated thicknessess; this is indicative of a combination of reduced alcohol permeabilities and changed electrokinetics on PtRu anode catalysts at high $\mathrm{pH}$. $V_{O C V}$ values for the AAEM-DAFCs were higher with ethanol than with methanol (consequent on lower permeability to ethanol), but were lower with ethylene glycol. Promisingly, and contrary to Nafion equivalents, peak power densities were not reduced when $\mathrm{C}_{2}$ alcohols (C-C bond containing) replaced methanol.

Keywords: Alkaline Membrane Fuel Cells, Alcohol Permeability, Direct Alcohol Fuel Cells, Open Circuit Voltage; Alkaline Ionomers 


\section{Introduction}

Traditionally, polymer electrolyte fuel cells have incorporated proton-exchange membranes (PEMs) such as Nafion ${ }^{\circledR}$ produced by Du Pont (Fig. 1a). However, alkaline anion-exchange membranes (AAEMs) are being developed for application in hydrogenand alcohol- fuelled metal-cation-free alkaline polymer electrolyte fuel cells (Figure 1b): an alkaline ionomer replaces aqueous potassium hydroxide, the electrolyte in traditional alkaline fuel cells (AFCs) [1]. Conductivities of $>0.03 \mathrm{~S} \mathrm{~cm}^{-1}$ at $30^{\circ} \mathrm{C}$ have been observed for fully-hydrated radiation-grafted-type AAEMs [2], contrary to the previous wisdom that the conductivities of AAEMs were too low for successful application in fuel cells. When operated in metal-cation-free mode, an AAEM performed for $>230 \mathrm{~h}$ in methanol/air fuel cell with minimal performance loss $(<100$ $\mu \mathrm{V} \mathrm{h}^{-1}$ ) [3]; the performances of traditional AFCs (aqueous $\mathrm{KOH}$ - mobile metal cations present result in the formation of metal carbonate precipitates) collapse to unacceptable levels after only a few hours when operated in methanol/air mode.

The principle, and widely touted, advantage of using alkaline ionomers in fuel cells, rather than the traditional acidic PEMs, is the potential use of non-Pt catalysts in the electrodes [4,5]. A recent combined study involving in situ a.c. electrochemical impedance spectroscopy and d.c. fuel cell testing has demonstrated that cathodes containing $\mathrm{Ag} / \mathrm{C}\left(4 \mathrm{mg}_{\mathrm{Ag}} \mathrm{cm}_{\mathrm{geo}}{ }^{-2}\right)$ perform as well as those containing $\mathrm{Pt} / \mathrm{C}\left(0.5 \mathrm{mg}_{\mathrm{Pt}}\right.$ $\mathrm{cm}_{\text {geo }}{ }^{-2}$ ) [6]. Furthermore, this study demonstrated that the major limiter of power performance was the restricted mass-transport of water to the cathode catalyst sites: water is now a stoichiometric reactant $\left(\mathrm{H}_{2} \mathrm{O}(g / l)+1 / 2 \mathrm{O}_{2}(g)+2 \mathrm{e}^{-} \rightarrow 2 \mathrm{OH}^{-}(\right.$membrane $)-$ see Fig. 1b). This inherent disadvantage can be offset with the use of thin AAEMs, which facilitate back-transport of water that has been electro-generated at the anode (i.e. 
$\mathrm{H}_{2}(g)+2 \mathrm{OH}^{-}($membrane $\left.) \rightarrow 2 \mathrm{H}_{2} \mathrm{O}(l / g)+2 \mathrm{e}^{-}\right)$. Despite this, power densities at $50^{\circ} \mathrm{C}$ of $>120 \mathrm{~mW} \mathrm{~cm}^{-2}$ can be achieved in $\mathrm{H}_{2} / \mathrm{O}_{2}$ fuel cell tests with thin $(51 \mu \mathrm{m})$ AAEMs [7]. The aim of this study is to evaluate the alcohol permeabilities of AAEMs, in order to assess their suitability for application in direct alcohol fuel cells (DAFCs). Low permeabilities are mandatory because thin AAEMs are necessary for minimised ionomer resistances and maximised water transport to the cathode catalyst sites. Initial indications, from a fuel cell study of a commercial AAEM (Morgane ${ }^{\circledR}$ ADP, Solvay S.A., Belgium), suggest AAEMs exhibit reduced methanol permeability compared to Nafion [8]. Liquid methanol $[9,10]$ and ethylene glycol $[4,11]$ fuels (volumetric energy densities of 6.1 and $5.3 \mathrm{~kW} \mathrm{~h} \mathrm{dm}^{-3}$ respectively $-c f .2 .6 \mathrm{~kW} \mathrm{~h} \mathrm{dm}^{-3}$ for liquid hydrogen) have both been evaluated previously in metal-cation-containing AAEM-DAFCs $\left(\mathrm{M}^{+} \mathrm{OH}^{-}\right.$salts added to the aqueous alcohol fuel supply) where promising power densities were reported; ethylene glycol electro-oxidation on Pt appears to be especially facile in aqueous potassium hydroxide and potassium carbonate solutions $(\mathrm{pH}>7$ electrolytes) [12]. Ethanol $\left(8.0 \mathrm{~kW} \mathrm{~h} \mathrm{dm}^{-3}\right)$ was also selected for evaluation in this study as it is a representative carbon-neutral biofuel.

\section{Experimental}

Two AAEMs were selected from a previous investigation (AAEM-E and AAEM-C in reference [2]) for evaluation in this study alongside Nafion-115 (benchmark); membrane pre-treatment procedures were unaltered. A selection of relevant physical properties for these polymer electrolytes is presented in Table 1. All statistical data in this study below relate to one sample standard deviation from the mean of multiple measurements over different samples of the same membranes. The alkaline membranes, 
synthesised and stored in the $\mathrm{Cl}^{-}$anion form, were not converted to the hydroxide forms until immediately prior to any experiments being conducted on them. From our experience, the hydroxide-anion-form AAEMs do not carbonate in air to any significant extent as has been verified by FT-Raman spectroscopy (which is very sensitive to the presence of $\mathrm{CO}_{3}{ }^{2-}$ and $\mathrm{HCO}_{3}{ }^{-}$species).

The solvent uptake related properties at room temperature were evaluated as follows. The gravimetric solvent uptakes, SU, were determined using:

$$
S U=\frac{m_{S}-m_{d r y}}{m_{d r y}} \times 100 \%
$$

where $m_{S}$ is the mass of the ionomers after submersion in each undiluted solvent (water, methanol, ethanol, ethylene glycol) for 1 week and $m_{d r y}$ is the mass of the solvent free ionomer that was dried for 7 days in a desiccator over anhydrous $\mathrm{CaCl}_{2}$ (s) (relative humidity $\mathrm{RH}=0 \%$ ) prior to immersion in the solvents. The thicknesses of the membranes when dry and when solvent swollen were recorded with an outside micrometer $(2 \mu \mathrm{m}$ precision); these values are used to indicate the degree of swelling. The solvent contents (molecules of solvent per $\mathrm{OH}^{-}$anion) were evaluated using:

$$
\lambda=\frac{S U}{M W_{S} \times I E C_{d r y} \times 100 \%}
$$

where $S U(\%)$ is the solvent uptake defined above, $I E C_{d r y}$ is the ion-exchange capacity of the dry ionomer $\left(\mathrm{mmol}\left(\mathrm{OH}^{-} / \mathrm{H}^{+}\right) \mathrm{g}^{-1}\right)$, and $M W_{S}$ is the relative molecular mass of the particular solvent used.

The alcohol permeabilities at $20 \pm 2^{\circ} \mathrm{C}$ were evaluated using the methodology described by Nasef et al. [13]. In summary, the ionomer was clamped between two chambers of a permeation cell (the set-up used was identical to that described in Figure 3 of reference [14]) so that $4.9 \mathrm{~cm}^{2}$ areas of each side of the membrane (that were directly aligned) 
were exposed to the contents of the chambers. Chamber A (the feed) was filled with aqueous methanol solution $\left(V_{A}=55 \mathrm{~cm}^{3}, C_{A}=15 \%\right.$ mass $)$ and chamber B (the permeate) was filled with grade II water $\left(V_{B}=50 \mathrm{~cm}^{3}\right)$. The concentration of methanol in chamber B $\left(C_{B}\right)$ was monitored over time by removing $0.1 \mathrm{~cm}^{3}$ samples; a CSi Series 200 gas chromatograph with flame ionisation detector and a SolGel-WAX capillary column (SGE, Ringwood, Australia, $20 \mathrm{~m} \times 0.25 \mathrm{~mm}$ i.d. and $1 \mu \mathrm{m}$ film thickness) were used for determination of the alcohol concentrations in these permeate samples. The permeability was calculated as follows [13]:

$$
P=\alpha \times \frac{V_{B} \times t}{A \times C_{A}}
$$

where $P / \mathrm{cm}^{2} \mathrm{~s}^{-1}$ is the alcohol permeability $(=D \times K$ where $D$ is the alcohol diffusivity and $K$ is the partition coefficient), $\alpha$ is the slope of $C_{B} v s$. time plot, $t$ is the ionomer thickness and $A$ is the area of ionomer exposed to the solutions.

Each membrane was studied at $50^{\circ} \mathrm{C}$ in a DAFC fuelled with each alcohol using an Arbin Fuel Cell Test Station. Electrodes $\left(25 \mathrm{~cm}^{2}\right)$ were supplied by E-Tek division of PEMEAs (Somerset, NJ, USA); the anodes contained unsupported PtRu (1:1 atomic ratio, $4 \mathrm{mg}_{\text {metal }} \mathrm{cm}_{\text {geo }}{ }^{-2}$ ) catalyst on "type-A" carbon cloth (PTFE binder), and the cathodes contained unsupported Pt black $\left(4 \mathrm{mg}_{\mathrm{Pt}} \mathrm{cm}_{\mathrm{geo}}{ }^{-2}\right)$. The electrode treatment and membrane electrode assembly (MEA) fabrication procedures and fuel cell testing protocols were as previously described [6]. The anodes were supplied with pre-heated $\left(50^{\circ} \mathrm{C}\right)$ aqueous alcohol solutions $\left(2 \mathrm{~mol} \mathrm{dm}{ }^{-3}, 10 \mathrm{~cm}^{3} \min ^{-1}, \lambda_{\text {stoic }}=7.8\right.$ at $\left.i=1 \mathrm{~A} \mathrm{~cm}^{-2}\right)$. The cathodes were supplied with flowing oxygen $\left(50^{\circ} \mathrm{C}, \mathrm{RH}=100 \%, 2 \mathrm{dm}^{3} \mathrm{~min}^{-1}, \lambda_{\text {stoic }}\right.$ $=23$ at $i=1 \mathrm{~A} \mathrm{~cm}^{-2}$ ). No back-pressurisation was used in any fuel cell test. For each MEA the testing was conducted in the order methanol $\rightarrow$ ethanol $\rightarrow$ ethylene glycol (in 
order of the number of potentially poisoning electro-oxidation products - see Section 3.2). The fuel cell performance parameter of principle interest in relation to fuel crossover is the open circuit voltage $\left(V_{O C V} / \mathrm{V}\right)$.

\section{Results and Discussion}

\subsection{Alcohol uptakes and permeabilities}

The solvent uptake properties of the membranes are presented in Fig. 2(a-c). It is evident that the AAEMs exhibit a lower affinity towards methanol, ethanol and ethylene glycol than Nafion-115; this is most notable for methanol. Whereas the number of alcohol molecules per exchange group $(\lambda)$ are significantly lower compared to water for the AAEMs, this is not the case for the combination of PEM and methanol; this high affinity towards methanol explains the undesirably high level of methanol crossover that has been observed in fuel cell tests with this PEM. Nafion shows a substantially lowered $\lambda_{E}$ (ethanol) compared to $\lambda_{M}$, (methanol) as does AAEM-C; AAEM-E shows similar $\lambda$ 's with all three alcohols (within experimental precision). As previously reported [2], the water content of AAEM-C is restricted compared to AAEM-E and to Nafion, due to the presence of additional cross-linking.

Nafion exhibits a higher degree of swelling compared to the AAEMs for most solvents. The thickness increases, $t_{i n c}=100 \% \times\left(t_{s}-t_{d r y}\right) / t_{d r y}$, with methanol are $47 \%$ for Nafion, $20 \%$ for AAEM-C and $27 \%$ for AAEM-E; the corresponding values for ethanol are $49 \%, 22 \%$ and $30 \%$ respectively. It has been previously reported that Nafion swells to a larger extent in ethanol than methanol, as measured by gravimetric solvent uptake experiments $[15,16]$, and that this is the primary cause of extensive delamination of Nafion-based MEAs in direct ethanol fuel cells. The ex situ results in this study, with 
undiluted alcohols, suggest that there is only a small increase in swelling with ethanol for Nafion-115 compared to the case with methanol; however, increases in thickness do not represent a complete picture of the swelling behaviour of Nafion as swelling can occur parallel to the electrodes (i.e. dimensional changes in the ionomer area), which can lead to considerable mechanical stresses within the MEA. The situation with ethylene glycol is not so clear cut, particularly in view of the low swelling of Nafion in this solvent $\left(t_{i n c}=26,20\right.$ and $35 \%$ for Nafion-115, AAEM-C and AAEM-E respectively). It was observed that white translucent regions form when Nafion is immersed in ethylene glycol; this could indicate that highly viscous ethylene glycol affects morphology / microstructure of that PEM.

Figure 3 presents the ex situ alcohol permeabilities for the polymer electrolyte membranes. The low alcohol contents for the AAEMs reported above have directly translated into desirably lower alcohol permeabilities compared to Nafion. $P_{M}=(1.9 \pm$ 0.9) $\times 10^{6} \mathrm{~cm}^{2} \mathrm{~s}^{-1}$ recorded for Nafion agrees with the value of $(1.8 \pm 0.1) \times 10^{6} \mathrm{~cm}^{2} \mathrm{~s}^{-1}$ previously reported by Holdcroft et al. for Nafion-117 [17]. The ethanol permeabilities are lower than the methanol permeabilities for all membranes. Previous studies in the literature report lower ethanol permeabilities compared to methanol for Nafion $[16,18]$ (despite the higher levels of dimensional, particularly area, swelling as discussed above); the issue of whether ethanol crossover has a more or a less pronounced effect on the cathode potential is still subject to debate $[16,19]$.

It is important to appreciate that the permeabilities measured in this study are ex situ. Fig. 1 shows the fundamental change in the direction of ionic conduction on replacement of the PEM with an AAEM. With a PEM the proton-conduction is in the same direction as alcohol crossover (i.e. electro-osmotic drag exacerbates alcohol 
crossover), but with an AAEM the two processes oppose; hence significantly reduced fuel crossover can be anticipated (especially at higher current densities). However, ex situ measurements are still valid as most fuel cell performance losses due to fuel crossover occur at low current densities, where the concentration of alcohol at the anode side of the ionomer is highest (i.e. where the concentration of alcohol in the catalyst layers adjacent to the electrolyte membrane has not been depleted due to significant rates of alcohol oxidation).

\subsection{DAFC performance tests}

The DAFC performance curves for each membrane fuelled with each alcohol are presented in Fig. 4(a-c). The performance parameter affected the most by in situ alcohol crossover through the MEA is the open circuit voltage $\left(V_{O C V} / \mathrm{V}\right)$ and these values are presented in Table 2. Enhanced fuel crossover generally leads to a lowering of $V_{O C V}$. Caution is required though when comparing different systems: for example, differences between oxygen reduction on Pt in alkali and in acid (i.e. differences in electrokinetic parameters such as exchange current density) and varying levels of catalyst poisoning, from the diverse range of reaction intermediates and products formed when using different fuels, can both have a marked effect on $V_{O C V}$. Methanol is a $\mathrm{C}_{1}$ alcohol, whilst ethanol and ethylene glycol are $\mathrm{C}_{2}$ alcohols with $\mathrm{C}-\mathrm{C}$ bonds to break. Adsorbed carbon monoxide, $\mathrm{CO}_{\mathrm{ads}}$, is a major intermediate in the mechanism of the methanol oxidation reaction (MOR) [20,21], whilst additional species such as acetaldehyde and acetic acid are generated in the ethanol electro-oxidation reaction (EOR) [22,23]; an extended range of potentially poisoning intermediates, such as glycolic and oxalic acids, are generated in the ethylene glycol oxidation reaction (EGOR) [24-26]. 
AAEM-C (same hydrated thickness as Nafion-115) exhibits superior $V_{O C V}$ 's to Nafion for all fuels; this relates well to the permeability data above. The thinner AAEM-E shows inferior $V_{O C V}$ 's to Nafion will all fuels; however, considering that the thickness has been halved (increased absolute crossover levels), these values are still better than expected. It is also evident from Table 2 that the reduced ethanol permeability compared to methanol that was observed for the AAEMs correlates well with the improved $V_{O C V}$ 's observed. However, despite the reduced ethanol permeability compared to methanol for Nafion, the $V_{O C V}$ is lower with the latter fuel; this is indicative of either amplified catalyst poisoning, from the presence of EOR intermediates, or poor EOR kinetics when in an acidic environment. The $V_{O C V}$ 's were consistently lower with ethylene glycol than with the other two fuels for all membranes (despite the lower ethylene glycol permeabilities compared to methanol); this is not surprising when considering the complexity, and the number of potentially poisoning intermediates, of the EGOR. Notwithstanding this, the $V_{O C V}$ 's for the AAEMs with ethylene glycol compared well with the value obtained for Nafion; this is in line with the previous reports of electrokinetically facile EGOR in high $\mathrm{pH}$ media [12].

The poor DAFC power densities produced with the AAEMs are evident in Figure 4 and Table 2. The current hypothesis is that a major contributor to these low performances is the poor reactant mass transport characteristics of the employed electrodes (as discussed in detail in reference [6]); no electrode architecture is currently available that has been specifically tailored/optimised for use in solid-state AAEM-based alkaline fuel cells.

A remarkable trend was observed regarding the relative performances of the three different fuels. The power performance was substantially decreased with the Nafioncontaining cells when replacing methanol with ethanol and ethylene glycol. However, 
the AAEM-based cells exhibited no such decrease in peak power densities; a higher peak power density was even observed with the $\mathrm{C}_{2}$ alcohols on testing of the thicker AAEM. The performance increases with ethanol and ethylene glycol are localised at low current densities where electrokinetic factors predominate; this is consistent with the $V_{O C V}$ data presented above and is in line with prevailing wisdom in that the electrochemical rates of EOR and EGOR are superior in alkaline media than in low pH systems. The anticipated performance increases on continued optimisation of the AAEM-based MEAs (especially with the development of electrode architectures that are specifically tailored for use in AAEM-DAFCs) will allow further investigation of these promising EOR and EGOR characteristics. Carbon dioxide gas bubbles were not observed in the anode outlet of the DAFCs with ethanol and ethylene glycol, contrary to what was observed with methanol; this suggests that the electrochemical reactions with these fuels are terminating before the complete $12 \mathrm{e}^{-}$and $10 \mathrm{e}^{-}$oxidations to $\mathrm{CO}_{2}$ respectively. Beyond this initial observation, the nature of the electro-oxidation products of the AAEM-DAFCs have not been characterised to date.

\section{Summary}

Alkaline anion-exchange membranes (AAEM) exhibit reduced methanol, ethanol and ethylene glycol permeabilities when compared to Nafion proton-exchange membrane (PEM). The reduced permeabilities directly contribute to the higher open circuit voltages of direct alcohol fuel cells (when the alkaline and acidic ionomers being compared are of similar thicknesses); this leads to the possibility of using thinner alkaline polymer electrolytes of lower absolute ionic resistances (to offset the intrinsically lower $\mathrm{OH}^{-}$conductivities in AAEMs compared to $\mathrm{H}^{+}$conductivities in 
PEMs). Initial observations indicate that ethanol and ethylene glycol oxidation electrokinetics on PtRu catalysts are improved compared to methanol with the use of alkaline ionomers.

\section{Acknowledgments}

The authors gratefully thank the U.K.'s Engineering and Physical Sciences Research Council for funding (Grant GR/S60709/01) and Keith Lovell (Defence Academy of the United Kingdom, Cranfield University, Shrivenham) for $\gamma$-ray irradiation.

\section{References}

1 J.R. Varcoe, R.C.T. Slade, Fuel Cells, 5 (2005) 187-200.

2 J.R. Varcoe, Phys. Chem. Chem. Phys., DOI: 10.1039/b615478f (2007).

3 J.R. Varcoe, R.C.T. Slade, E. Lam How Yee, Chem. Commun., (2006) 1428-1429.

4 C. Coutanceau, L. Demarconnay, C. Lamy, J.-M. Léger, J. Power Sources, 156 (2006) 14-19.

5 K. Matsuoka, Y. Iriyama, T. Abe, M. Matsuoka, Z. Ogumi, J. Power Sources, 150 (2006) 27-31.

6 J.R. Varcoe, R.C.T. Slade, G.L. Wright, Y. Chen, J. Phys. Chem. B, 110 (2006) 21041-21049.

7 J.R. Varcoe, R.C.T. Slade, E. Lam How Yee, S.D. Poynton, D.J. Driscoll, Chem. Mater., DOI: 10.1021/cm062407u (2007).

8 E.H. Yu, K. Scott, J. Power Sources, 137 (2004) 248-256.

9 E.H. Yu, K. Scott, J. Appl. Electrochem., 35 (2005) 91-96.

10 A. Huang, C. Xia, C. Xiao, L. Zhuang, J. Appl. Polym. Sci., 100 (2006) 2248-2251. 
11 Z. Ogumi, K. Matsuoka, S. Chiba, M. Matsuoka, Y. Iriyama, T. Abe, M. Inaba, Electrochemistry, 70 (2002) 980-983.

12 K. Matsuoka, M. Inaba, Y Iriyama, T. Abe, Z. Ogumi, M. Matsuoka, Fuel Cells, 2 (2002) 3539.

13 M.M. Nasef, N.A. Zubir, A.F. Ismail, M. Khayet, K.Z.M. Dahlan, H. Saidi, R. Rohani, T.I.S. Ngah, N.A. Sulaiman, J. Membr. Sci., 268, 2006, 96-108.

14 M.M Nasef, N.A. Zubir, A.F. Ismail, K.Z.M. Dahlan, H. Saidi, M. Khayet, J. Power Sources, 156 (2006) 200-210.

15 S. Song, G. Wang, W. Zhou, X. Zhao, G. Sun, Q. Xin, S. Kontou, P. Tsiakaras, J. Power Sources, 140 (2004) 103-110.

16 S. Song, W. Zhou, Z. Liang, R. Cai, G. Sun, Q. Xin, V. Stergiopoulos, P. Tsiakaras, Appl. Catal. B: Environ., 55 (2005) 65-72.

17 A. Siu, B., Pivovar, J. Horsfall, K.V. Lovell, S. Holdcroft, J. Polym. Sci. B: Polym. Phys., 44 (2006) 2240-2252.

18 S Song, P. Tsiakaras, Appl. Catal. B: Environ. 63 (2005) 187-193.

19 V.A. Paganin, E. Sitta, T. Iwasita, W. Vielstich, J. Appl. Electrochem., 35 (2005) $1239-1243$.

20 X. Zhang, K.-Y., Tsang, K.-Y. Chan, J. Electroanal. Chem., 573 (2004) 1-9.

21 W.L. Holstein, H.D. Rosenfeld, J. Phys. Chem. B, 109 (2005) 2176-2186.

22 S. Rousseau, C. Coutanceau, C. Lamy, J.-M. Léger, J. Power Sources, 158 (2006) $18-24$.

23 C. Lamy, S. Rousseau, E.M. Belgsir, C. Coutanceau, J.-M. Léger, Electrochim. Acta, 49 (2004) 3901-3908. 
24 K. Matsuoka, Y. Iriyama, T. Abe, M. Matsuoka, Z. Ogumi, Electrochim. Acta, 51 (2005) 1130-1139.

25 C. Lamy, E.M., Belgsir, J.-M. Léger, J. Appl. Electrochem., 31 (2001) 799-809.

26 A.O. Neto, T.R.R. Vasconcelos, M. Linardi, E.V. Spinacé, R.W.R.V. da Silva, J. Appl. Electrochem., 35 (2005) 193-198. 
Figure 1: Schematic comparison of PEM- (a) and AAEM-containing (b) fuel cells.

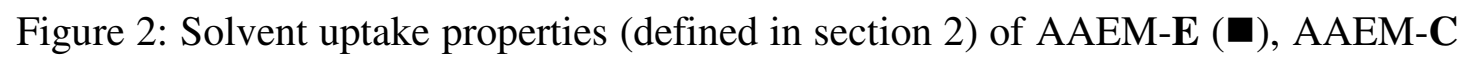
$(\boldsymbol{\nabla})$ and Nafion-115 (-) at room temperature. $\mathrm{D}=$ fully dehydrated, $\mathrm{W}=$ water, $\mathrm{M}=$ methanol, $\mathrm{E}=$ ethanol and $\mathrm{EG}=$ ethylene glycol. $S U$ is solvent uptake, $\lambda=$ solvent molecules per exchange group and $t=$ membrane thickness.

Figure 3: Solvent permeabilities of AAEM-E ( $\mathbf{\square})$, AAEM-C ( $\boldsymbol{\nabla})$ and Nafion-115 ( at room temperature. $\mathrm{M}=$ methanol, $\mathrm{E}=$ ethanol and $\mathrm{EG}=$ ethylene glycol.

Figure 4: Direct alcohol fuel cell performance curves at $50^{\circ} \mathrm{C}$ for (a) AAEM-E, (b) AAEM-C and (c) Nafion-115 with methanol (•), ethanol ( $\boldsymbol{\nabla})$ and ethylene glycol (ם). Filled symbols represent $V_{\text {cell }}$ and open symbols represent $P_{\text {cell }}$. 
Table 1

Selected properties of the various polymer electrolytes [2]

\begin{tabular}{|c|c|c|c|}
\hline & AAEM-E & AAEM-C & Nafion-115 \\
\hline Exchange group & $-\mathrm{N}^{+} \mathrm{Me}_{3} \mathrm{OH}^{-}$ & $-\mathrm{N}^{+} \mathrm{R}_{3} \mathrm{OH}^{-}$ & $-\mathrm{SO}_{3}^{-} \mathrm{H}^{+}$ \\
\hline Notes & radiation-grafted ETFE & additional cross-links & \\
\hline$I E C_{d r y}{ }^{\mathrm{a}} / \mathrm{mmol} \mathrm{g}^{-1}$ & $1.03 \pm 0.11$ & $1.14 \pm 0.02$ & $0.93 \pm 0.07$ \\
\hline$t_{F H}^{\mathrm{b}} / \mu \mathrm{m}$ & $74 \pm 2$ & $153 \pm 4$ & $153 \pm 3$ \\
\hline$t_{d r y}^{\mathrm{b}} / \mu \mathrm{m}$ & $60 \pm 2$ & $135 \pm 2$ & $121 \pm 3$ \\
\hline$W U^{\mathrm{c}}(\%)$ & $40 \pm 5$ & $28 \pm 2$ & $40 \pm 2$ \\
\hline$\lambda_{F H}^{d}$ & $21 \pm 3$ & $14 \pm 1$ & $24 \pm 2$ \\
\hline$\sigma_{F H}{ }^{\mathrm{e}} / \mathrm{S} \mathrm{cm}^{-1}$ & $0.030 \pm 0.005$ & $0.033 \pm 0.002$ & $0.093 \pm 0.008$ \\
\hline
\end{tabular}

${ }^{\mathrm{a}}$ Ion-exchange capacity. ${ }^{\mathrm{b}}$ Ionomer thickness. ${ }^{\mathrm{c}}$ Gravimetric water uptake $=100 \% \mathrm{x}$ $\left(m_{F H}-m_{d r y}\right) / m_{d r y}$, where $m$ represents the ionomer masses. ${ }^{\mathrm{d}}$ Water content (number of water molecules per $\mathrm{OH}^{-}$anion). ${ }^{\mathrm{e}}$ Through plane (normal) conductivity at $30^{\circ} \mathrm{C}$ in water evaluated from 2-probe electrochemical impedance spectroscopic data. FH and dry represents fully hydrated fully dehydrated ionomers respectively.

Table 2

Selected fuel cell test data extracted from Fig. 4.

\begin{tabular}{|c|c|c|c|c|c|c|}
\hline & \multicolumn{2}{|c|}{ AAEM-E } & \multicolumn{2}{|c|}{ AAEM-C } & \multicolumn{2}{|c|}{ Nafion-115 } \\
\hline & $\begin{array}{l}V_{O C V} \\
/ \mathbf{m V} \\
\end{array}$ & $\begin{array}{c}P_{\text {max }} \\
\mathbf{m W} \mathbf{~ c m}^{-2}\end{array}$ & $\begin{array}{l}V_{O C V} \\
/ \mathbf{m V} \\
\end{array}$ & $\begin{array}{c}P_{\max } \\
/ \mathrm{mW}_{\mathbf{c m}^{-2}}\end{array}$ & $\begin{array}{l}V_{O C V} \\
/ \mathbf{m V} \\
\end{array}$ & $\begin{array}{c}P_{\max } \\
/ \mathrm{mW}^{-2}\end{array}$ \\
\hline $\mathbf{M}$ & 565 & 2.16 & 701 & 1.17 & 655 & 30.6 \\
\hline $\mathbf{E}$ & 632 & 2.09 & 749 & 1.71 & 636 & 7.42 \\
\hline EG & 513 & 1.99 & 604 & 1.57 & 550 & 8.6 \\
\hline
\end{tabular}

